\title{
Community-based initiatives and their relation to poverty reduction and health development: experiences in the Eastern Mediterranean Region
}

Mohammad Assai Ardakani ${ }^{1}$

\section{Introduction}

Human development does not depend simply on national income; it goes far beyond that. It is "about creating an environment in which people can develop their full potential and lead productive, creative lives in accord with their needs and interests... Development is thus about expanding the choices people have to lead lives that they value" [1]. In order to have more choices requires building human capabilities, i.e. the things that people can do or be in life. "The most basic capabilities for human development are to lead long and healthy lives, to be knowledgeable, to have access to the resources needed for a decent standard of living and to be able to participate in the life of the community" [1].

The United Nations Conference on Environment and Development held in Rio de Janeiro, Brazil, in June 1992, led to the famous Rio declaration stating as principle 1 that "Human beings are at the centre of concerns for sustainable development. They are entitled to a healthy and productive life in harmony with nature" [2].
Earlier, the Universal Declaration of Human Rights adopted by United Nations General Assembly Resolution 217A (III) of December 10, 1948 stipulated that all the individuals in society are equally entitled to the right of access to public services, social security, work, and free choice of employment. It is also said, "Everyone has the right to a standard of living adequate for the health and well-being of himself and of his family, including food, clothing, housing and medical care and necessary social services" [3]. In poor countries, fulfilment of these rights remains a great challenge.

Poverty is a multidimensional concept: the most popular definitions relate poverty to income or to the provision of the basic needs. An often used definition of the poverty line is an income of US\$ 1 per day per person. Poverty can also be viewed from the basic needs perspective where poor families are characterized by frequent illness, low birth weight, low education, social or political marginalization, and discrimination based on gender or age or other [4].

It has been shown that health and development go hand in hand; they have a

${ }^{1}$ Regional Adviser, Community-based Initiatives, World Health Organization Regional Office for the Eastern Mediterranean, Cairo, Egypt (Correspondence to Mohammad Assai Ardakani: assaim@emro.who.int). 
reciprocal influence on each other and each enhances the effects of the other. Health deteriorates with poor socioeconomic conditions and is generally poor in circumstances where development is lagging. The poor health conditions associated with underdevelopment and poverty reduce productivity and worsen other aspects of life. On the other hand, holistic development improves health which further enhances levels of development.

Poverty remains one of the main causes of ill-health because poor people are less likely to have access to good quality healthcare services, proper education, safe water and sanitation and other basic needs. According to the World Health Organization (WHO), approximately 1.2 billion people in the world live in extreme poverty. Those people are five times more likely to die before reaching the age of 5 years, and two and half times more likely to die between the ages of 15 and 59 years, compared to those living in higher-income groups. Moreover, the gap between the rich and poor is growing with serious implications for health [5].

A less recognized reality is that improved health status can alleviate vulnerability and offer a route out of poverty. Both macro- and microeconomic studies indicate that better health translates into greater and more equitably distributed wealth because it builds human capital and increases productivity. Indeed, healthy children are better able to learn, while healthy breadwinner adults are more able to work and care for their families. The health sector has thus sufficient incentives to justify engaging in poverty reduction initiatives, and needs to develop both the skills and infrastructures necessary to work in partnership with other sectors and the community.

In the past few decades, the health sector has proved its catalytic role in health pro- motion, triggering appropriate initiatives for improving health and quality of life of communities. This effort was promoted within the WHO Eastern Mediterranean Region (EMR) through community-based initiatives (CBI) composed of basic development needs (BDN), healthy villages programme, healthy cities programme, and women in health and development, which have provided opportunities to integrate health interventions in local development processes. These initiatives have implemented flexible strategies at the local level in different cultures and societies by actively involving communities and the related sectors. The CBI approach addresses the major socioeconomic determinants of health within a broad perspective of development and creates access to the essential social services to provide optimum equity at the grass-roots level. The outcomes of these initiatives provide clear evidence that health is a human capital and investment to promote comprehensive development results in the improved quality of life and well-being of the communities [6].

This paper discusses how WHO/EMRO has advocated the importance of alleviating poverty in order to improve the health of individuals and their communities and fulfil other socioeconomic needs through community ownership and intersectoral collaboration.

\section{Concept of community-based initiatives}

The concept of CBI is a continuum of WHO's definition of health that encompasses a holistic approach to health with as much significance ascribed to the social well-being of the individual as to physical and mental health. In fact, CBI can be seen as an extension of primary health care that

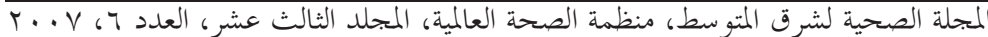


focuses on the whole range of health determinants and addresses the related issues with the application of innovative ideas and appropriate technologies. CBI also recognizes and fosters the mutual links between health and multisectoral development, with proactive participation of the communities.

EMRO has been advocating poverty reduction as one of the most potent strategies to facilitate equitable development in order to achieve health-related goals, which will have a positive impact on the overall environment and quality of life of individuals and the community [7].

The CBI concept is an integrated bottom-up socioeconomic development concept, which is based on full community involvement supported through intersectoral collaboration. It is a self-sustained people-oriented strategy that addresses the diverse basic needs of the community and recognizes health as a socially cohesive factor. Community-based initiatives offer the added value of overcoming inequity which has positive implications for health. The most salient aspects of this approach are the organization, mobilization and enhancement of community capabilities and involvement in micro-development through social and income-generating schemes. These have an impact on basic needs, which constitute the most powerful determinants of good health, quality of life and productivity (Figure 1)

The CBI concept takes into account the interdependent needs of the countries, both within and outside the health sector, such as primary health care including nutrition and reproductive health, basic education, provision of shelter, safe drinking-water and sanitation. Projects have included establishing health centres, training community health workers and volunteers on health issues, using the community to accelerate the Expanded Programmes on Immunization, raising awareness on reproductive health and nutrition, implementing directly observed treatment, short-course (DOTS) for tuberculosis through community participation, organizing literacy classes and women's vocational training, establishing

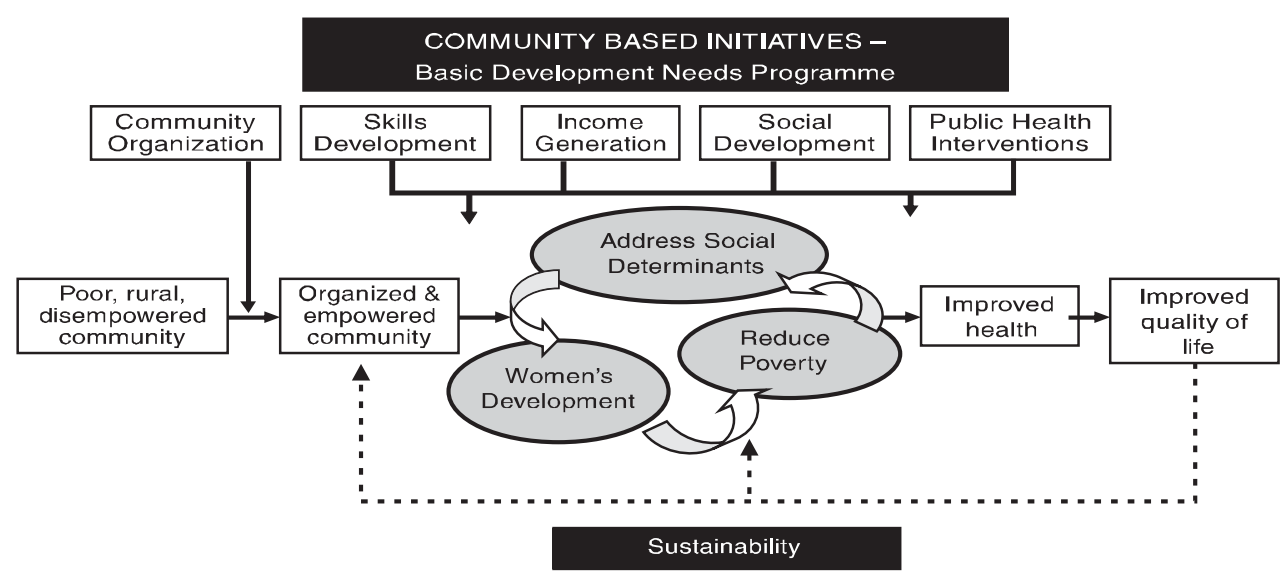

Figure 1 Tackling the social determinants of health through the basic development needs component of community-based initiatives 
libraries and community-based information centres, supporting agriculture and livestock projects, and tree planting. The provision of microcredit schemes for income generation also falls within the purview of CBI. All these activities are, however, preceded by an elaborate exercise aimed at organizing and mobilizing the community with an emphasis on their enhanced awareness of health issues, active participation, gender mainstreaming and self-reliance. Local cluster representatives (CRs), district authorities and public sector line departments contribute and complement each other in programme implementation.

Representatives from various line departments constitute the $\mathrm{CBI}$ intersectoral teams, which are instrumental in providing the requisite guidance in building local organizations to enhance community involvement. The teams offer technical assistance in priority areas for community action related to social development and poverty reduction. These teams vigilantly support the implementation process of carefully selected social and income-generating ventures and develop an interactive working relationship with village/community development committees. They also constitute the bridge that conveys community concerns and perceived needs and priorities to the relevant line departments of the district government. CBI teams are thus helpful in generating the trust and confidence necessary for building a solid partnership between the government and civil society organizations. Furthermore, in most of the villages within the CBI area of operation, women's organizations are established to spearhead women's development activities at the community level.

Provision of interest-free loans for income-generating schemes targets the poorest members of the community with defined criteria. This is included as an in- tegral part of the responsibilities of the village/community development committees who manage this revolving fund. The CBI intersectoral team reviews the feasibility of the proposals prior to finalization. The loans are repaid on instalment to the village development committee once the project is operational so that the money can be redistributed to other needy members of the community.

The CBI interventions assume added relevance for the countries of the Eastern Mediterranean in the light of a recent WHO initiative, the Commission for the Social Determinants of Health (CSDH). The social determinants of health refer to both specific features and pathways by which societal conditions affect health and which can potentially be altered by informed action. Many of the inequalities in health, both within and between countries, can be understood in terms of inequalities in the social conditions in which people live and work, such as literacy, housing, employment, etc. These social determinants of daily life have a major impact on health status and on general well-being. Tackling such underlying causes of poor health can contribute to improving health and health equity. CBI is thus seen as an appropriate grass-roots intervention to address key social determinants of health in EMR and beyond $[8]$.

\section{CBI status in the Eastern Mediterranean Region}

The basic development needs programme, the healthy villages programme, the healthy cities programme and the women in health and development programme are being implemented in 17 countries in EMR. Currently, these interventions cover a population of 17503841 people.

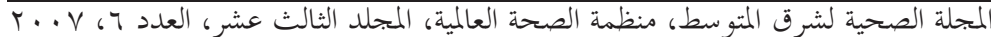


EMRO is advocating the sustainability of CBI interventions as a vital strategy during the programme expansion in the member countries. This is achieved through community involvement in programme management, partnership approaches and institutionalization of the programme as an integral part of the system. Member States have demonstrated different degrees of institutionalizing CBI within the national development policy. For instance, Bahrain, Islamic Republic of Iran, Iraq, Jordan, Morocco, Oman, Pakistan, Saudi Arabia, Sudan, Syrian Arab Republic and Yemen have established a unit responsible for CBI within the Ministry of Health. Jordan, Pakistan and Syrian Arab Republic have also allocated an annual budget for maintenance and expansion of the programme. Jordan, Pakistan, Sudan and Syrian Arab Republic have linked the programme with national and international nongovernmental organizations. Djibouti, with the consent of 5 other ministries as well as the Ministry of Health, has included basic development needs as part of the national health and development strategy. This is a promising action paving the way for more programme expansion. Other countries implementing $\mathrm{CBI}$ are in the process of integrating the community-based approach within their health and development plans.

The Regional Office assists countries in developing model areas to implement CBI. These model areas can serve as the operational research projects and the basis for subsequent expansion to a national programme.

Figure 2 shows the improvement in health and in other social indicators in countries where the CBI programme has been evaluated.

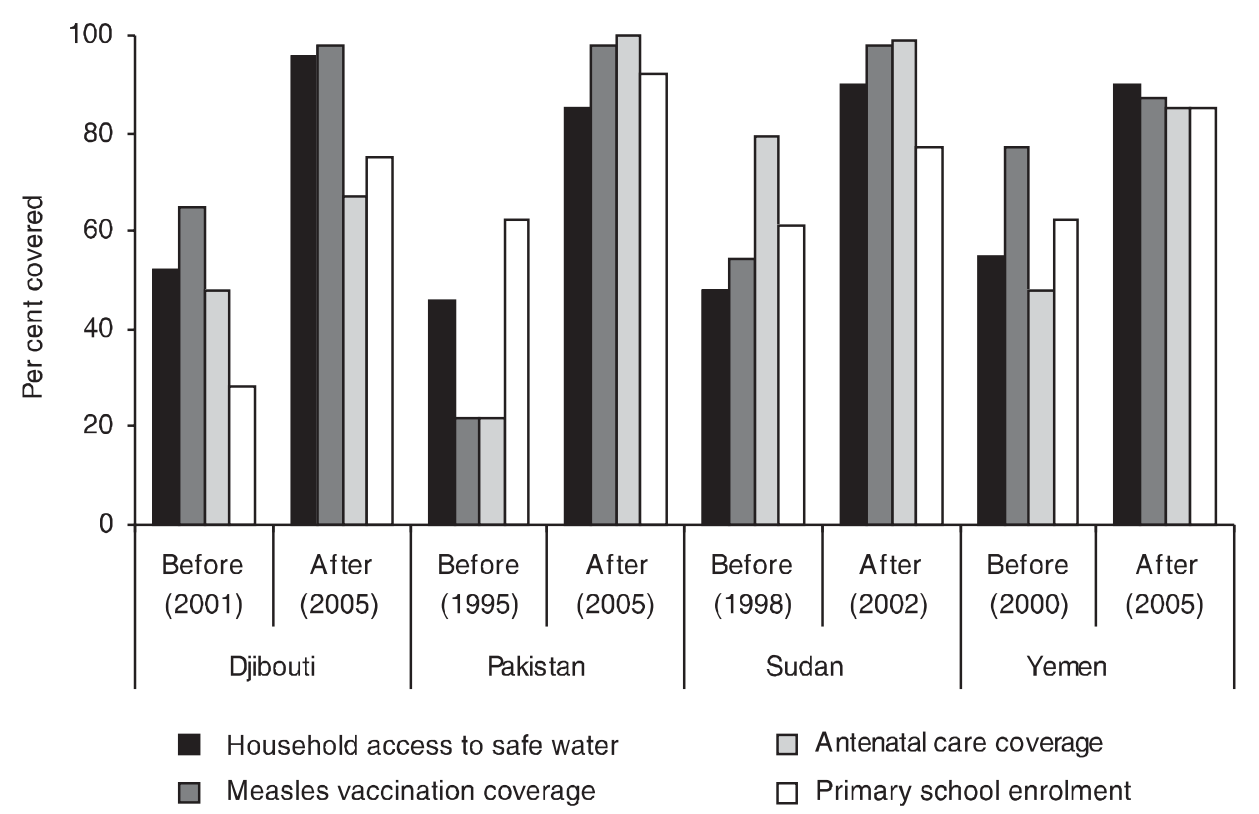

Figure 2 Improvement in health and social indicators in areas with a basic development needs programme 


\section{Towards sustainable community-based initiatives}

Commitment of the national and local governments, collaboration with civil society and some form of external financial support are essential to meet the challenge of sustainability and scaling up of CBI. Monitoring, evaluation and documentation need to be improved, but at the same time care is needed not to compromise the participation of community members in the process of data collection and management, as this is essential to the local feeling of project "ownership". Nor must the emerging leadership roles of local women be undermined if work through formal government channels ignores the community voice.

Plans for future interventions build on current CBI experiences. Thus there are plans to expand community-based strategies to control malaria, tuberculosis and HIV/AIDS, applying the lessons learned from CBI. One objective is to make DOTS available in all BDN areas of the Region by the end of 2007. Another key intervention is the preparation of a plan to expand community-based health insurance schemes in Pakistan, Sudan and Yemen in 2008.

The experience in countries of the EMR with CBI, where health is central to the development process, provides a useful model for other regions for providing interventions at the grass-roots level that address the social determinants of health. CBI is especially effective in overcoming gender discrimination and in providing a social environment that supports women's development. Despite the effectiveness of CBI, the major challenge is its full ownership by the community and its institutionalization within national health and development policies and programmes. WHO continues its technical support to Member States to overcome these challenges and make CBI a part of the national health and development plans. This will eventually improve the quality of life of the people, particularly the poor and most vulnerable groups of the community.

\section{References}

1. United Nations Development Programme. Human Development Reports website (http://hdr.undp.org/hd, accessed 17 July 2007).

2. World Summit on Sustainable Development. Outcomes of the World Summit on Sustainable Development and implications for follow-up. Executive Board, 111th Session (EB111/31) (http://www.who. int/gb/ebwha/pdf_files/EB111/eeb11131. pdf, accessed 17 July 2007)

3. Universal Declaration of Human Rights. United Nations General Assembly ResoIution 217A (III) of December 10, 1948 (http://www.un.org/Overview/rights.html, accessed 17 July 2007)).
4. Poverty reduction begins with children New York, United Nations Children's Fund, 2000.

5. Guidelines and tools for management of basic development needs. Cairo, World Health Organization Regional Office for the Eastern Mediterranean, 2000 (http:// www.emro.who.int/CBI/PDF/BDN/BDN_ Guidelines.pdf, accessed 17 July 2007).

6. Sheikh $\mathrm{R}$ et al. CBI - lessons learnt and way forward. Paper presented in the 22nd Annual Meeting of the Regional Director with WHO Country Representatives and Regional Office Staff, Cairo, Egypt, February 2007

المجلة الصحية لشرق المتو سط، منظمة الصحة العالمية، المجلد الثالث عشر، العدد ب، V... 
7. Mohamud KB. The basic development needs concept "community solutions to community problems". Healthy cities, healthy villages quarterly journal, 2001, 3 (A publication of the Ministry of Health and Medical Education, Islamic Republic of Iran).
8. Assai M, Siddiqi S, Watts S. Tackling social determinants of health through community based initiatives. British medical journal, 2006, 333(7573):854-6.

\section{El Miño and malaria}

The term El Miño is nowadays used to refer to periods of strong and prolonged warm weather in the eastern Pacific which influence the climate worldwide. Events occur every $2-7$ years and last around 12-18 months. They begin with the weakening of the prevailing winds in the Pacific and a shift in rainfall patterns; the warm waters are accompanied by changes of air pressure in the Pacific. The whole cycle is now referred to as EI Miño Southern Oscillation (EMSO). The regions where El Miño has a strong effect on climate are those with the least resources: southern Africa, parts of South America, South-East Asia.

The El Miño phenomenon provides good opportunities to study effects of climate variability on human health. Research is centred on the ability to predict El Miño events: seasonal forecasts are used to predict major climate trends for anything from several months to a few seasons ahead and are much more reliable during El Miño.

WHO is a member of the United Mations Inter-Agency Task Force on El Miño, which aims to develop strategies towards prevention, preparedness and mitigation as regards El Miño-induced disasters. EMSO is associated with increased risks of some of the diseases transmitted by mosquitoes, such as malaria, dengue and Rift Valley fever.

Malaria transmission is particularly sensitive to weather conditions. In some highland regions of the world, higher temperatures possibly linked to El Miño may increase transmission. This has been shown to occur in higher latitude parts of Asia such as northern Pakistan. A pilot study on the application of seasonal forecasting to malaria control has been undertaken in southern Africa.

WHO's "Roll Back Malaria" initiative targets control efforts to years when there is a high-risk of El Miño, increasing the cost-effectiveness of malaria control; the judicious use of insecticides can also delay the development of resistance. 